\section{Prosopagnosie oder die (Un-)Fähigkeit, Gesichter zu erkennen}

\author{
E. Taverna
}

Der berühmte "coup de foudre» dauert eine Viertelsekunde. Dann schlägt die Liebe ein wie der Blitz, oder es tut sich, gemäss zahlreichen Studien, nichts. Die berühmte Fallstudie des Neurologen Oliver Sacks vom «Mann, der seinen Hut mit seiner Frau verwechselte» belegt, dass es zum Erkennen eines lebendigen Gesichtes einen intakten assoziativen Cortex braucht. Bis zum Erkennen des eigenen Gesichtes im Spiegel braucht ein Neugeborenes 18 Monate. Nur der Mensch und die Menschenaffen sind zu einer Leistung fähig, die ausschliesslich die rechte Gehirnhälfte erbringen kann. Diese wenigen Beispiele belegen, dass wir heute viel über unser Gehirn und seine Wirklichkeit wissen und das menschliche Gesicht dennoch nichts von seinem Geheimnis verloren hat.

\section{Vom Gottesbild ...}

Die oft erwähnte Ausstellung im Kunstmuseum Zürich zeigte vorwiegend das Studienmaterial von Johann Caspar Lavater (1741-1801), des Diakons der Stadtkirche St. Peter, der seiner Portraitsammlung ein ganzes Vermögen opferte. Lavater, der Vater der Physiognomik, verstand seine Forschung als Wissenschaft, als eine Topographie des Antlitzes, das die systematische Ableitung des Charakters und der Fähigkeiten ermöglichen würde. "Lasset uns sehen, ob man nicht alle Vernunft mit Füssen trete, wenn man zwischen dem inneren Charakter und dem äusserlichen Willkührlichkeit annimmt. Lässt sich nicht zum voraus aus der Vernunft sagen, dass ein krankes und blödes Auge ganz anders als ein gesundes und scharfes aussehen müsse?» Die rund 600 Bilder und Objekte zeigten ihn als missionarischen Menschenverbesserer, als Kommunikationsgenie, das eine riesige Briefkorrespondenz bewältigte, als obsessiven Sammler eines auswuchernden physiognomischen Kunstkabinetts. Seine Wissenschaft gründete auf dem sehenden Beobachten. Das Bild war ihm Argument und Beweis, das er mit einem moralisierenden Kommentar versah: "Zarte, jungfräuliche Unschuld, Herzensgüte ohne grosse Geisteskraft - Lauernd und erzschlau Trockenheit, Steifheit mehr als froher, offener Klarsinn - Witz und Laune schwebt und Treu auf der froheren Lippe - Häusliche Treue und Geschäfftigkeit im kleinen Zirkel, in der Küche und auf dem Estrich.
Herzgute, hausmütterliche Mädchen frohen Sinnes, leichter munterer Bewegung - galant und theatralisch."

Seine «Fragmente zur Menschenkenntnis und Menschenliebe» standen unter dem Motto der Gottesebenbildlichkeit des Menschen. In jedem Portrait versuchte er das unerreichbare Urbild Christi zu entdecken. Die Ausstellung wäre noch viel interessanter gewesen, wenn sie den weiteren Weg von Lavaters Ideen verfolgt hätte.

\section{... zur Verbrechervisage}

Zahlreiche Schulen, Eignungs- und Laufbahnberater, Heilpraktiker und Managementseminare berufen sich bis heute auf die Psycho-Physiognomik von Carl Huter (1861-1912). Der gelernte Portrait- und Porzellanmaler schrieb als Autodidakt zahlreiche Bücher wie «Menschenkenntnis» und "Vom Empfindungsvermögen der Materie». Seine Naturellehre postuliert nicht nur im Maiglöckchen den zarten Empfindungstypus, sondern auch die elektrische Energie beim disharmonischen Körperbau des moralisch-idiotischgemeingefährlichen geborenen Verbrechers. Ein zeitgenössisches Beispiel seiner Gesichtsdeutung ist die Analyse von Joschka Fischer, dem deutschen Aussenminister: "Die gespannte Breitform von Kopf und Gesicht zeigt ein hohes, aggressives Potential, die breite Nasenwurzel ein überdurchschnittliches Sprechtalent, die kräftige Stirne weist auf strategische Intelligenz hin und die schräg gestellten Ohren belegen seine Impulsivität usw.»

Musste Lavater noch teure Ölgemälde aufkaufen, so machte es die Photographie seinen Nachfolgern leichter. Die Christussuche des Mitglieds der Helvetischen Gesellschaft ist kein Thema mehr. Polizei, Justiz, Anthropologie und Physiognomie klassifizieren und inventarisieren den gesellschaftlichen Feind. Die ersten Photographien für Identifikationszwecke entstanden 1843 in Brüssel und zeigten Dienstmädchen, Prostituierte, Arbeiter und Obdachlose. Der Pariser Kriminologe Alphonse Bertillon erfand Körpermasse und besondere Kennzeichen. Der Psychiater Cesare Lambroso gründete 1880 in Turin eine Sehschule für den geborenen Schurken. Auch er war ein passionierter Sammler, der mit seinen Artefakten die negative, visuelle Beweisführung auf den Charakter übertrug. Die Praxis setzte sich fort in der Kategorisierung des typischen Aussenseiters und in biologistische Konzepte, die Mediziner und Juristen zur Rassenforschung und systematischen Erfassung von psychisch Kranken, körperlich Behinderten, Alkoholikern, Homosexuellen, Juden, Sinti und Roma entwickelten.

Der neuste Stand, Gesichter zu analysieren, zeigt sich in der zunehmenden öffentlichen Videoüberwachung, die jeden Bürger nach biometrischen Gesichtspunkten in Sekundenschnelle für Fahndungszwecke analysiert. 
Die utopische Entdeckungsreise ist noch nicht zu Ende. Angesichts seiner zahlreichen, esoterischen oder unmenschlichen Nachfolger haben wir heute keinen Grund, über Lavaters naive Ideen zu lächeln. Die nonverbalen Botschaften der Physiognomie lassen sich weder theologisch kommentieren noch mit
Huter als Entfaltung von Keimblättern erklären, auch nicht nach Lambroso typisieren oder rassenkundlich vermessen. Die Erkenntnis, dass wir innerhalb von 250 Millisekunden lieben oder hassen, oder unseren Partner mit einem Hut verwechseln, sollte uns etwas vorsichtiger gemacht haben.

\section{Ärzte werden nie krank}

\author{
N. Lindt
}

Dass ich einem Arzt mein Leben verdanke, sagt im Grunde schon alles. Er hiess Doktor Glatthaar, und er wickelte mir in Sekundenschnelle die Nabelschnur vom Hals, als ich zur Welt kam. Ich bin ihm später nie mehr begegnet. Doch sein Name begleitet mich heute noch, denn mit ihm hat alles begonnen. Ich lebte!

Ich wuchs und gedieh, die ersten Jahre vergingen, aus dem Kleinkind wurde ein Kind, und ich entdeckte die Welt. Ich lernte, was ein Briefträger ist, was ein Polizist und ein Milchmann ist - und ich lernte auch, was ein Arzt ist. Der erste Doktor in meiner Kindheit war unser Hausarzt. Er war ein richtiger Landarzt, unterwegs von Patient zu Patient, immer etwas verspätet, immer in Eile, und ich sehe ihn heute noch vor mir, wie er grossgewachsen und raschen Schrittes ins Haus kam.

Stärker noch als sein Bild allerdings ist mir sein Geruch in Erinnerung - der medizinische Aether, der aus der schweren schwarzen Arzneitasche stieg, die er mit sich brachte. Meistens kam er zu meiner Grossmutter, die im unteren Stock wohnte. Er setzte sich zu ihr ins Wohnzimmer, immer auf denselben Stuhl, und die Arzneitasche stellte er neben sich.

Sie war wie die Werkzeugtasche eines Elektrikers; und ich glaube mich zu erinnern, dass unser Arzt grosse Hände hatte, grosse und warme Hände, die er nicht nur zum Pillenverschreiben benutzte. Er fasste uns an. Er drückte, fühlte und prüfte, und er schlug mit dem Hämmerchen gegen das Knie. Das war immer der Höhepunkt, wenn er sein Hämmerchen aus der Werkzeugtasche hervornahm. Ich weiss noch heute nicht ganz genau, wozu dieses Hämmerchen gut war, aber darauf kam es nicht an. Es war eine mystische Handlung.

Korrespondenz:

Nicolas Lindt

Ferchacherstrasse 14

CH-8636 Wald
Der Autor dieses Beitrages lebt als freier Schriftsteller in Wald im Zürcher Oberland. Neben seiner literarischen Tätigkeit traut er Brautpaare ausserhalb der Kirche.

"Was Nicolas Lindt auszeichnet», schrieb die Neue Zürcher Zeitung, «sind die lebendige Schilderung, eine unbekümmert ehrliche Haltung und eine ernsthafte Suche nach dem, was den Sinn der menschlichen Biografie bestimmen könnte.»

Von Nicolas Lindt sind erhältlich:

"Vollmond über Weissbad" (Liebesgeschichten)

"Aus heiterem Himmel» (Erzählungen)

«Familienglück» (DRS-1-Radioroman)

«Die Befreiung - mein Weg zu einem persönlichen Denken"

"Die Freiheit der Sternenberger"

(Reiseberichte \&t Dorfgeschichten)

"Der Spieler von Zürich» (Bericht)

"Beobachtungen aus dem Hinterhalt» (Prosa)

"Der Asphalt ist nicht die Erde -

das Zürcher Selnau"

ausserdem

"Wilhelm Tell für Fortgeschrittene»

(die Ansprache in Sils-Maria am 1. August 2000)

$\mathrm{Zu}$ beziehen in jeder Buchhandlung oder - noch besser - direkt beim Autor in 8636 Wald, Tel./Fax 0552466888 .

Unser Hausarzt, wenn er zu uns kam, war kein Besucher wie andere. Er war der Herr Doktor, und ich beobachtete, wie die Erwachsenen, meine Eltern und meine Grossmutter, genau befolgten, was er ihnen auftrug. Sie widersprachen ihm nie. Unser Hausarzt war eine freundliche, unfehlbare Autorität. Er stand höher als meine Eltern, höher als alle Erwachsenen, die ich kannte, er war kein gewöhnlicher Mensch.

Mit diesem Doktorbild bin ich aufgewachsen. Das Bild gefiel mir, es gehörte für mich zu einer Welt, die in Ordnung war, und ich fand es immer wieder bestätigt. Der Vater meines Schulkameraden zum Beispiel durfte seinen Wagen auch an Orten parkieren, wo Parkieren verboten war: Er durfte es, weil er Arzt war. Ebenso durfte er kostenlos mit seiner Frau ins Theater gehen: Weil er nebenamtlich Theaterarzt war. 